\title{
The use of an unpleasant sound as the unconditional stimulus in aversive Pavlovian conditioning experiments that involve children and adolescent participants
}

\author{
David L. Neumann, Allison M. Waters, and H. Rae Westbury \\ Griffith University, Gold Coast, Queensland, Australia
}

\begin{abstract}
Ethical considerations can prohibit the use of traditional unconditional stimuli (USs), such as electric shocks or loud tones, when children or adolescents participate in aversive Pavlovian conditioning experiments. The present study evaluated whether an unpleasant sound provides a viable alternative. Fifteen boys and girls aged 13 to 17 years completed a differential Pavlovian conditioning procedure in which a conditional stimulus (CS) was followed by the sound of metal scraping on slate. Acquisition of conditioned responses was found in startle blink magnitude, expectancy judgments of the sound, and skin conductance responses. Extinction of conditioned responses was found in all measures when the CS was no longer followed by the unpleasant sound. Subjective ratings and skin conductance responses indicated that the sound was unpleasant because of its qualitative features, rather than its intensity. The results support the use of an unpleasant sound as a low-risk alternative to traditional USs in aversive Pavlovian conditioning experiments with children and adolescents.
\end{abstract}

In aversive Pavlovian conditioning, a neutral conditional stimulus (CS) is paired with an aversive unconditional stimulus (US). In research with healthy adults, researchers have traditionally used a US that is mildly painful or intense-most commonly, electric shocks and loud tones (Grillon, 2002; Lissek et al., 2005). However, these stimuli present several ethical limitations when the participants are healthy children and adolescents or are individuals with neurodevelopmental disorders. An electric shock requires the individual to determine an intensity that is "unpleasant, but not painful" during a work-up procedure. Children and adolescents may not be sufficiently self-aware to make this judgment. Loud tones (e.g., $100 \mathrm{~dB}$ presented for $1 \mathrm{sec}$ ) may cause pain and discomfort in children and adolescents who are sensitive to loud stimuli-particularly those who have fragile $\mathrm{X}$ syndrome, autistic spectrum disorders, or some anxiety disorders (American Psychiatric Association, 1994). In addition, loud tones may be associated with poor acquisition of conditioned responses (CRs) in experiments with children (e.g., Liberman, Lipp, Spence, \& March, 2006). Unpleasant odors (e.g., Flor, Birbaumer, Hermann, Ziegler, \& Patrick, 2002) and air puffs (e.g., Suboski, 1967) are alternatives to traditional USs, but these require special stimulus delivery systems, and obtaining compliance may be difficult in some children (e.g., avoiding movement).

Another stimulus that may function as a viable US in studies with children is a sound that is unpleasant, not be- cause of its intensity, but because of its inherent characteristics. The psychoacoustic properties of a range of sounds were studied by Halpern, Blake, and Hillenbrand (1986) in a sample of adults. The sounds included white noise, a blender motor, compressed air sounds, and rubbing two pieces of Styrofoam together, among others. The sound that was rated as being most unpleasant was produced by dragging a three-pronged garden tool across slate. Neumann and Waters (2006) made a recording of this type of sound and confirmed its effectiveness when used as a US in a Pavlovian conditioning procedure with adult college students. In addition, the unpleasant sound was rated as being more unpleasant than electric shocks and loud tones, although the electric shock elicited larger skin conductance defense responses than did the sound. It was suggested that the sound was effective because of its unpleasant qualitative features rather than its high intensity.

The unpleasant sound may present several advantages in aversive Pavlovian conditioning experiments with children and adolescents. For example, it is presented at only a moderate intensity, does not require subjective calibration via a work-up procedure, and uses equipment found in the typical laboratory (computer and headphones or speakers). However, it needs to be empirically demonstrated that children and adolescents will perceive the sound to be unpleasant and that it can serve as a viable US in an aversive Pavlovian conditioning procedure in this age group. For example, it is possible that younger participants may perceive the sound of metal scraping on slate to be less

D. L. Neumann, d.neumann@griffith.edu.au 
unpleasant than do adults because of their shorter learning history and less opportunity for prior exposure.

\section{Evaluation of the Unpleasant Sound in a Pavlovian Conditioning Procedure}

\section{Method}

Participants and Apparatus. To evaluate the effectiveness of the unpleasant sound in a Pavlovian conditioning procedure, 7 boys and 8 girls between 13 and 17 years of age $(M=16.00$ years, $S D=$ 1.19) participated in a protocol that had been approved by the Griffith University Human Research Ethics Committee. The methods followed those described by Neumann and Waters (2006). A differential conditioning procedure was used (Öhman, Hamm, \& Hugdahl, 2000) by pairing one CS (CS+) with the unpleasant sound and presenting another $\mathrm{CS}(\mathrm{CS}-)$ alone during conditioning. Both were presented alone during a subsequent extinction phase. The CSs were outlines of a diamond and of a triangle presented for $8 \mathrm{sec}$. The US was a 3-sec recording of a three-pronged garden fork being scraped over slate (see Neumann \& Waters, 2006) that did not exceed a peak intensity of $83 \mathrm{dBA}$. The resulting sound resembled that of fingernails scratching down a chalkboard. Pavlovian CRs were indexed by (1) modulation of the startle blink reflex that was elicited by $50 \mathrm{msec}$ of white noise presented at $110 \mathrm{dBA}$, (2) self-reported US expectancy, and (3) skin conductance responses (SCRs). These measures were selected because they are among those most commonly employed for measuring aversive Pavlovian conditioning in experiments with children, adolescents, and adults (e.g., Lissek et al., 2005), and they encompass both signal-based and affective learning measures. The startle blink data from 2 participants were not used, due to nonresponsiveness.

Procedure. Participants were instructed that they would be presented with pictures of geometric shapes and an "unusual sound." They were asked to predict when the sound might occur and to indicate this by using an expectancy dial. The expectancy dial could be moved across the two extremes of "certain sound will occur" and "certain sound will not occur" and a middle "uncertain" region. During conditioning, there were eight positive trials followed by the unpleasant sound US, interspersed with eight negative trials. Intertrial intervals (ITIs) were randomly varied among 20, 25, and $30 \mathrm{sec}$. Extinction trials for both trial types followed immediately and were interspersed in a similar manner. Half of the trials (7,500 msec following the CS onset) and half of the ITIs contained a blink-eliciting stimulus. Startle blinks were measured as the maximum response, occurring $20-200 \mathrm{msec}$ following the onset of the blink-eliciting stimulus. Trials that did not contain a blink-eliciting stimulus were used to measure SCR magnitude as the SCR-CR (latency window of 1-4 sec) and SCR-UR (latency window of $9-13 \mathrm{sec})$.

\section{Results}

To examine the strength of conditioning, the dependent measures were arranged into two blocks of trials during each of the conditioning and extinction phases and analyzed with separate CS $\times$ block ANOVAs. Table 1 shows the relevant statistical effects obtained for each dependent measure. Conditioning of startle blink reflexes and SCR-CRs was confirmed by significantly larger responses during the $\mathrm{CS}+$ than during the $\mathrm{CS}-$. The difference between the $\mathrm{CS}+$ and $\mathrm{CS}-$ varied across blocks for expectancy judgments and SCR-URs. The interaction for expectancy reflected that the expectancy of the US increased across blocks for CS $+(t=4.62, p<.01)$, whereas it decreased for CS- $(t=2.99, p<.05)$. The interaction for SCR-URs reflected that there was a significant decline across blocks for CS $+(t=10.18, p<.01)$, but not for CS $-(t=2.40, p>.05)$. The extinction of startle blink reflexes, SCR-CRs, and SCR-URs was confirmed by the lack of significant differences between the $\mathrm{CS}+$ and $\mathrm{CS}-$. The extinction of expectancy judgments was reflected in the higher expectancy of the US during $\mathrm{CS}+$ than during $\mathrm{CS}-$ in Block $1(t=9.73, p<.01)$, but not in Block $2(t=2.16, p>.05)$.

The results showed that the unpleasant sound of metal scraping on slate supported the acquisition and extinction of CRs in the entire sample of 13- to 17-year-old boys and girls. Conditioned responding was established in measures typically regarded as representative of fear learning (modulation of startle blink), autonomic conditioning (skin conductance responses), and expectancy learning (selfreported ratings). In addition, startle blink potentiation, often described as fear-potentiated startle (Grillon, 2002), was observed only during the CS paired with the unpleasant sound. The effect sizes $\left(\eta_{\mathrm{p}}^{2}\right)$ obtained for the difference between the CS + and CS- during conditioning for the startle blink, expectancy, and skin conductance measures

Table 1

Mean Startle Blink Magnitude ( $\mu \mathrm{V})$, Ratings of Unconditional Stimulus (US) Expectancy (\%), Skin Conductance $(\sqrt{\mu \mathrm{S}})$ Conditioned Response (SCR-CR), and Unconditioned Response (SCR-UR) or Its Omission for the CS + and CS - in Both Trial Blocks During the Conditioning and Extinction Phases, and Their Associated Statistical Effects

\begin{tabular}{|c|c|c|c|c|c|c|c|c|c|c|c|c|c|}
\hline \multirow[b]{3}{*}{ Measure } & \multirow[b]{3}{*}{ Effect } & \multirow[b]{3}{*}{$d f$} & \multirow[b]{3}{*}{$F$} & \multirow[b]{3}{*}{$p$} & \multirow[b]{3}{*}{$\eta_{\mathrm{p}}^{2}$} & \multicolumn{4}{|c|}{$\mathrm{CS}+$} & \multicolumn{4}{|c|}{$\mathrm{CS}-$} \\
\hline & & & & & & \multicolumn{2}{|c|}{ Block 1} & \multicolumn{2}{|c|}{ Block 2} & \multicolumn{2}{|c|}{ Block 1} & \multicolumn{2}{|c|}{ Block 2} \\
\hline & & & & & & $M$ & $S D$ & $M$ & $S D$ & $M$ & $S D$ & $M$ & $S D$ \\
\hline \multicolumn{14}{|c|}{ Conditioning } \\
\hline Startle blink & $\mathrm{CS}$ & 1,12 & 8.59 & $<.01$ & .42 & 141.20 & 84.19 & 103.70 & 78.16 & 120.20 & 92.78 & 80.98 & 75.39 \\
\hline Expectancy & $\mathrm{CS} \times$ block & 1,14 & 29.05 & $<.0005$ & .68 & 29.13 & 28.10 & 98.37 & 5.92 & -38.93 & 37.68 & -83.73 & 45.51 \\
\hline SCR-CR & $\mathrm{CS}$ & 1,14 & 8.84 & $<.01$ & .39 & 1.02 & 0.56 & 0.97 & 0.70 & 0.70 & 0.52 & 0.71 & 0.57 \\
\hline SCR-UR & $\mathrm{CS} \times$ block & 1,14 & 31.13 & $<.0005$ & .69 & 1.92 & 0.59 & 0.90 & 0.63 & 0.44 & 0.24 & 0.17 & 0.25 \\
\hline \multicolumn{14}{|c|}{ Extinction } \\
\hline Startle blink & $\mathrm{CS}$ & 1,12 & 0.39 & $>.05$ & .03 & 100.50 & 70.09 & 67.83 & 62.87 & 92.31 & 74.97 & 65.39 & 51.80 \\
\hline Expectancy & $\mathrm{CS} \times$ block & 1,14 & 28.44 & $<.0005$ & .67 & 34.30 & 34.37 & -65.00 & 48.17 & -55.57 & 40.34 & -85.27 & 31.25 \\
\hline SCR-CR & $\mathrm{CS}$ & 1,14 & 0.43 & $>.05$ & .03 & 0.89 & 0.45 & 0.72 & 0.59 & 0.83 & 0.50 & 0.51 & 0.41 \\
\hline SCR-UR & $\mathrm{CS}$ & 1,14 & 1.01 & $>.05$ & .09 & 0.49 & 0.59 & 0.37 & 0.45 & 0.30 & 0.38 & 0.33 & 0.37 \\
\hline
\end{tabular}

Note-Expectancy ratings range on a scale from +100 (maximum expectation of the US) to - 100 (maximum expectation of no US). Skin conductance responses SCR-CR and SCR-UR were square root transformed prior to analyses in order to normalize the distributions. 
were, respectively, $.42, .95$, and .39 , indicating that the unpleasant sound produced a moderate to large conditioning effect. Moreover, these values are comparable to - and even exceed-those obtained by Neumann and Waters (2006) in their experiment with adults $(.40, .80$, and .33, respectively). Neumann and Waters also reported that the effect sizes obtained with an unpleasant sound US were similar to that obtained with electric-shock and loud-tone USs. When one considers the prior results and the present findings together, an unpleasant sound would seem to provide a reliable US for researchers who wish to study aversive Pavlovian conditioning in children and adolescents.

\section{Evaluation of Subjective Ratings to the Unpleasant Sound}

\section{Method \\ Participants, Apparatus, and Procedure. To examine the sub- jective properties of the unpleasant sound, we asked the same sample of participants to provide ratings to the unpleasant sound in compari- son to an electric shock, a loud tone ( $100 \mathrm{dBA}$ for $1,000 \mathrm{msec})$, and a blink reflex-eliciting stimulus ( $110 \mathrm{dBA}$ for $50 \mathrm{msec}$ ). The 200 -msec shock was set individually for each participant to be "unpleasant, but not painful" (final mean level was $5.77 \mathrm{~mA}, S D=2.07$ ). Partici- pants were presented with each stimulus in random order, and, after each presentation, they were asked to make ratings on 9-point linear scales for pleasantness $(0=$ very unpleasant, $8=$ very pleasant $)$, arousal $(0=$ very calm, $8=$ very arousing $)$, and interest $(0=$ very boring, $8=$ very interesting). The SCRs elicited 1-4 sec after each stimulus were also measured.}

\section{Results}

As shown in Table 2, the stimuli differed significantly in all subjective ratings and in SCRs, as assessed by a oneway ANOVA. The sample of boys and girls perceived the unpleasant sound to be, in fact, unpleasant, as shown by a mean pleasantness rating of 2.03 on a scale of 0 (very unpleasant) to 8 (very pleasant). Moreover, the unpleasant sound was rated as being more unpleasant than the loud tone and the electric shock (both $t \mathrm{~s}>2.50, p<.05$ ). On the other hand, the shock was rated as being more arousing than the loud tone $(t=4.39, p<.05)$, but the unpleasant sound did not differ from any stimuli (all $p \mathrm{~s}>$ $.05)$. The unpleasant sound and the electric shock were both rated as being more interesting than the loud tone (both $t \mathrm{~s}>4.89, p<.05$ ), and the shock was also rated as being more interesting than the blink-eliciting stimulus $(t=4.13, p<.05)$. Finally, skin conductance defense responses elicited by the shock were larger than those elicited by the unpleasant sound, tone, and blink-eliciting stimuli (all $t \mathrm{~s}>4.19, p \mathrm{~s}<.01$ ), which themselves did not differ (all $p$ s $>.05$ ). The magnitude differences seen in the SCRs may reflect the intensity of the stimulus, since the electric shock was set at a level determined by each individual to be "unpleasant, but not painful." This level was set during a shock work-up procedure and is the standard method for setting the intensity of this stimulus in Pavlovian conditioning experiments. Because the shock intensity was "unpleasant, but not painful," it may have been perceived to be unpleasant because it is presented at just below the pain threshold. In contrast, the moderateintensity unpleasant sound may have been perceived to be unpleasant due to its qualitative features. The pattern of results observed by Neumann and Waters (2006) with a sample of adult college students using subjective ratings was similar to the pattern of results found in the present research, with a mean pleasantness rating of 1.46 on the same rating scale. The similar ratings suggest that the sound is perceived to be unpleasant to a similar degree across a wide age range.

\section{Conclusion}

The stimulus of the unpleasant sound of metal being scraped on slate was shown to support conditioning. Although it was subjectively rated as unpleasant, it was tolerable and presented fewer ethical concerns than other commonly used aversive stimuli, such as electric shocks and loud tones. On the basis of the strength of the conditioning effects observed in this study, it would seem likely that the application of the unpleasant sound to examine conditioning in very young children or children and adolescents with neurodevelopmental disorders would be successful.

\section{AUTHOR NOTE}

We thank Stephen Brandis and two anonymous reviewers for their comments on earlier drafts of this article. A computer file copy of the unpleasant sound used in this research may be obtained via e-mail on request. Correspondence concerning this article should be sent to D. L. Neumann, School of Psychology, Griffith University, Gold Coast Campus, Queensland, 4222, Australia (e-mail: d.neumann@griffith.edu.au).

Table 2

Mean Subjective Ratings for Pleasantness, Arousal, and Interest, and Mean Skin Conductance Defense Responses $(\sqrt{\mu \mathrm{S}})$ for the Unpleasant Sound, Shock, Loud Tone, and Blink-Eliciting Stimuli, and Their Associated Statistical Effects

\begin{tabular}{|c|c|c|c|c|c|c|c|c|c|c|c|}
\hline \multirow[b]{3}{*}{ Measure } & \multirow[b]{3}{*}{$F(3,42)$} & \multirow[b]{3}{*}{$p$} & \multirow[b]{3}{*}{$\eta_{\mathrm{p}}^{2}$} & \multicolumn{8}{|c|}{ Stimulus } \\
\hline & & & & \multicolumn{2}{|c|}{ Sound } & \multicolumn{2}{|c|}{ Shock } & \multicolumn{2}{|c|}{ Loud Tone } & \multicolumn{2}{|c|}{$\begin{array}{c}\text { Blink- } \\
\text { Eliciting }\end{array}$} \\
\hline & & & & $M$ & $\overline{S D}$ & $M$ & $S D$ & $M$ & $S D$ & $M$ & $S D$ \\
\hline Pleasantness rating & 3.39 & $<.039$ & .19 & 2.03 & 2.11 & 3.47 & 1.85 & 3.73 & 1.16 & 3.17 & 1.94 \\
\hline Arousal rating & 6.51 & $<.002$ & .32 & 4.20 & 2.81 & 5.70 & 1.44 & 2.97 & 2.02 & 4.50 & 2.61 \\
\hline Interest rating & 17.67 & $<.0005$ & .56 & 4.73 & 2.40 & 6.00 & 1.60 & 1.73 & 1.62 & 3.47 & 2.17 \\
\hline Skin conductance response & 11.63 & $<.0005$ & .45 & 1.04 & 0.59 & 2.09 & 0.95 & 0.74 & 0.81 & 0.97 & 0.63 \\
\hline
\end{tabular}

Note-Anchors for the ratings for pleasantness, 0 (very unpleasant) to 8 (very pleasant); for arousal, 0 (very calm) to 8 (very arousing); and for interest, 0 (very boring) to 8 (very interesting). 


\section{REFERENCES}

American Psychiatric Association (1994). Diagnostic and statistical manual of mental disorders: DSM-IV (4th ed.). Washington, DC: Author.

Flor, H., Birbaumer, N., Hermann, C., Ziegler, S., \& Patrick, C. J. (2002). Aversive Pavlovian conditioning in psychopaths: Peripheral and central correlates. Psychophysiology, 39, 505-518.

GrILlon, C. (2002). Startle reactivity and anxiety disorders: Aversive conditioning, context, and neurobiology. Biological Psychiatry, 52, 958-975.

Halpern, D. L., Blake, R., \& Hillenbrand, J. (1986). Psychoacoustics of a chilling sound. Perception \& Psychophysics, 39, 77-80.

Liberman, L. C., Lipp, O. V., Spence, S. H., \& March, S. (2006). Evidence for retarded extinction of aversive learning in anxious children. Behaviour Research \& Therapy, 44, 1491-1502.

Lissek, S., Powers, A. S., McClure, E. B., Phelps, E. A., WoldehawariAt, G., Grillon, C., \& Pine, D. S. (2005). Classical fear conditioning in the anxiety disorders: A meta-analysis. Behaviour Research \& Therapy, 43, 1391-1424.

Neumann, D. L., \& Waters, A. M. (2006). The use of an unpleasant sound as an unconditional stimulus in a human aversive Pavlovian conditioning procedure. Biological Psychology, 73, 175-185.

Öhman, A., Hamm, A., \& Hugdahl, K. (2000). Cognition and the autonomic nervous system: Orienting, anticipation, and conditioning. In J. T. Cacioppo, L. G. Tassinary, \& G. G. Berntson (Eds.), Handbook of psychophysiology (2nd ed., pp. 533-575). Cambridge: Cambridge University Press.

SubosKi, M. D. (1967). UCS intensity and the latency of the classically conditioned eyelid response. Journal of Experimental Psychology, 74, 31-35.

(Manuscript received June 19, 2007;

revision accepted for publication September 28, 2007.) 